\title{
Grubel-Lloyd Endeksi İle Endüstri-İçi Ticaret Analizi: Tarım Sektörü Türkiye Örneği
}

\section{Fatih MANGIR $^{1}$ Adem FIDAN $^{2}$}

${ }^{1}$ Doç.Dr., Selçuk Üniversitesi, İIBF, İktisat Bölümü, Konya

${ }^{2}$ Doktora Öğrencisi, Selçuk Üniversitesi, Sosyal Bilimler Enstitüsü, İktisat Programı

\section{Özet}

Tarım sektörü istihdam yaratması, temel gıda maddeleri ihtiyacını karşılaması, diğer sektörlere girdi sağlaması, ihracata katkısı ve ekonomik büyüme açısından önemli sektörlerden biridir. Aynı zamanda tarım sektörü dış ticareti ülke ekonomisinde önemli bir politika alanını oluşturmaktadır. Klasik dış ticaret teorileri endüstriler arasındaki dış ticaretin nedenlerini analiz etmektedir. Ancak ülkeler aynı endüstride farklılaştırılmış ürünlerin ticaretini yapmaktadır. Endüstri içi dış ticaretin analizi yapılırken en çok kullanılan Grubel-Lloyd endeksidir. 1971 yılında Herb Grubel ve Peter Lloyd tarafından geliştirilen bu indeks belirli ürünlerin endüstri içi ticaretini ölçmek için kullanılmaktadır.

Bu çalışmada, Türkiye'nin 1996-2016 dönemi tarım sektörünün endüstri içi dış ticaretinin analizinin yapılması amaçlanmıştır. Çalışma sonucu gıda sektöründe yüksek endüstri-içi seviyesi ortaya koymakta iken, hammadde tarım ürünlerinde düşük çıkmıştır. Sonuç tarım sektörü için önemli politika önerisi taşımaktadır.

Anahtar Kelimeler: Tarım Sektörü, Endüstri içi ticaret, Grubel-Lloyd Endeksi, Rekabet.

\section{Intra-Industry Trade Analysis With Grubel-Lloyd Index: Agricultural Sector, Turkey Case}

\begin{abstract}
The agricultural sector is one of the important sectors by creating employment, obtaining basic foods necessities, providing inputs into other sectors, contributing exports, and economic growth. At the same time, the foreign trade of agricultural sector constitutes an important policy area in the country's economy. Classical trade theories analyze the causes of foreign trade in inter-industries. However, countries trade with the differentiated products in intraindustry. The Grubel-Lloyd index is frequently used in analyzing the intra-industry trade. Developed by Herb Grubel and Peter Lloyd in 1971, this index is used to measure intra-industry trade of certain products.

In this study, it is aimed to analyze the intra-industry trade of agriculture sector in Turkey during the period of 1996-2016. The results of the study show high level of intra-industry trade in the food sector while it is low in raw-material products. The result has important policy implications for the agricultural sector in Turkey.
\end{abstract}

Key Words: Agriculture Sector, Intra-Industry Trade, Grubel-Lloyd Index, Competation

\section{Giriş}

Türkiye, dünya ekonomisinde değişime uyum sağlamak ve kendi ihtiyaçlarını da karşılamak adına kalkınmayı amaçlayarak sanayileşmeye ağırlık vermiştir. Cumhuriyetin ilk yıllarından günümüze kadarki süreçte sanayi sektörü ile tarım sektörü bu sebep ile dengeye gelmiş ve daha sonra sanayi sektörünün milli gelirden aldığı pay daha yüksek olmuştur. Tarım sektörünün hem milli gelirdeki payı düşmüş hem de toplam istihdamda payı azalmıştır. Ancak halen tüm dünya da olduğu gibi Türkiye'de de tarım sektörü önemini korumaktadir.

Tablo 1: Tarım Sektörü Temel Göstergeler

\begin{tabular}{|l|l|l|l|l|l|l|}
\hline & \multicolumn{3}{|c|}{2002} & \multicolumn{3}{|c|}{$\mathbf{2 0 1 6}$} \\
\hline & Türkiye & $\begin{array}{l}\text { Tarım } \\
\text { sektörü }\end{array}$ & $\begin{array}{l}\text { Tarım } \\
\text { Payı } \\
(\%)\end{array}$ & Türkiye & $\begin{array}{l}\text { Tarım } \\
\text { sektörü }\end{array}$ & $\begin{array}{l}\text { Tarım } \\
\text { Pay1 } \\
(\%)\end{array}$ \\
\hline $\begin{array}{l}\text { Nüfus } \\
\text { (Milyon) }\end{array}$ & 69.3 & 23.7 & 34.2 & 79.8 & 6.1 & 7.7 \\
\hline $\begin{array}{l}\text { İstihdam } \\
\text { (Milyon) }\end{array}$ & 21.3 & 7.4 & 34.7 & 27.2 & 5.3 & 19 \\
\hline $\begin{array}{l}\text { GSYIH } \\
\text { (Milyar\$) }\end{array}$ & 230.5 & 23.7 & 10.3 & 856.7 & 52.2 & 6.3 \\
\hline
\end{tabular}

Kaynak:TÜIK
Tarımın toplam ihracata katkısı 1998-99 y1lında \%17 civarlarından 2014-2015 yılına gelindiğinde \%11 `e gerilemiş; ithalattaki payı ise aynı yıllar için $\% 5$ civarlarında kalmıştır. Tarımın katma değeri ise \%12`lerden \%8`lere düşmüştür (TIM, 2016). Diş ticaret ve katma değerde yaşanan bu değişime rağmen istihdam, dış ticaretteki payı ve endüstriye sağladığı hammadde katkısı ile önemini korumaktadır. Dünya üretiminde7. sırada yer alan Türkiye'de 2016 yılında 28.7 milyon istihdamın yaklaşık 5'te biri tarım sektöründe çalışmaktadır. Tarım üretimi son 14 yılda $\% 40$ artış göstererek 2016 yılında 52,3 milyar ABD dolarına ulaşmıştır. Tarım aynı zamanda gıda, tütün, tekstil-giyim, deri, orman, kâğıt, gibi sektörlere önemli girdi desteği sağlamaktadır. Türkiye 2016 yılında 190'1 aşkın ülkeye 1781 tür tarım ürünü ihraç ederek 16,9 milyar ABD doları ihracat geliri elde etmiştir (TYDTA, 2017).

Geleneksel iktisat teorileri, tarım ile sanayi malları arasındaki bir başka ifadeyle endüstriler arasındaki dış ticaretin nedenlerini analiz eder. Ancak modern dünyada ülkeler arasında birbirleriyle çok kolay ikame edilebilen aynı endüstrinin farklılaştırılmış mallarının ticareti de yapılmaktadır. Günümüzde gelişmiş ülkeler arasındaki toplam ticaretin önemli bir k1smı aynı endüstrinin 
farklılaştırılmış mallarının ticareti bir başka ifadeyle endüstriiçi ticaret şeklindedir. Grubel Llyod (1975) endüstri içi ticareti sistematik olarak analiz eden ilk iktisatçılardır.

Bu çalışmanın amacı, Türkiye'nin 1996-2016 dönemi tarım sektörünün endüstri içi dış ticaretinin analizinin yapılmasıdır. Çalışmada ilk olarak Türkiye'nin tarım ürünleri dış ticaretinden bahsedilmiştir. Çalışmanın devamında ise endüstri içi ticaret teorisi ve ölçüm yöntemleri konularına ile literatüre değinilmiştir. $\mathrm{Bu}$ bölümde ise çalışmanın analiz bölümünde kullanacağımız Grubel-Lloyd endeksinden bahsedilmiştir. Çalışmanın son bölümünde ise Türkiye tarım sektörünün 1996-2016 dönemi Grubel-Lloydyöntemi ile endüstri içi dış ticaret analizi yapılmıştır. Buradaki temel amaç Türkiye'nin toplam tarım sektöründeki EIT'i ölçülürken ihracat ve ithalata konu olan ana kalemlerin toplam tarım sektörü EITT'deki rolünün ne olduğunun tespitidir.

Çalışmada sonuç olarak, tarım sektörü EİT'nin yüksek olduğu gözlemlenmiş ancak tarım sektörü alt kalemlerinde farklılıklar tespit edilmiştir. $\mathrm{Bu}$ farklılıkların nedenleri ve etkileri çalışmanın son bölümünde ayrıntılı olarak ele alınmıştır.

\section{Türkiye'nin Tarım Ürünleri Dış Ticareti}

1985'lere kadar Türkiye temel gida maddelerinde, kendine yetecek kadar üretim politikası uyguluyordu. Ancak sonrasındaki üretim ve ticaret politikaları Türkiye'yi ithalatçı konumuna getirmiş durumdadır (TÜİK, 2016). Türkiye'nin 1996 - 2016 dönemi ihracat ve ithalat verileri incelendiğinde; 21 yıllık dönem içerisinde yedi yıl (2000, 2003, 2007, 2008, 2010, 2011 ve 2012) toplam tarımsal dış ticarette ithalat ihracattan yüksek gerçekleşirken geri kalan on dört yılda ise ihracat ithalattan yüksek olmuştur. Yapılan bu değerlendirmeler SITC Revize 3 baz alınarak ortaya konulmaktadır.

Toplam tarımsal diş ticaretini oluşturan iki ana kalem bulunmaktadır. Bunlardan birincisi gida maddeleri kalemi iken, diğeri tarımsal hammaddeler kalemidir. Türkiye'nin tarımsal dış ticaretinde fazla ve eksik vermesinde alt kalemlerin etkisi oldukça fazladır. Şöyle ki alttaki tablo incelendiğinde gıda maddeleri dış ticaretinde iniş çıkışlar olmak ile beraber sürekli ihracat fazlası verilmiştir. Diğer taraftan tarımsal hammaddeler dıș ticaretinde ise sürekli olarak ithalat fazlası verilmiştir. Buda gösteriyor ki Türkiye son 21 yılda gida maddeleri diş ticaretinde net ihracatçı iken; tarımsal hammaddeler diş ticaretinde net ithalatçı konumundadir.

Türkiye 2011 yılında toplam tarımsal dış ticarette en yüksek dış ticaret açığını 2 Milyar 295 Milyon 316 Bin \$ ile gerçekleştirmiştir. $\mathrm{Bu}$ y1l için alt kalemler incelendiğinde gıda maddeleri dış ticaretinde 3 Milyar 554 Milyon 650 Bin \$ ihracat fazlası vermiştir. Ancak tarımsal hammaddeler dış ticaretine bakıldığında 5 Milyar 849 Milyon 966 Bin \$ ithalat fazlası vermiştir. Buda gösteriyor ki Türkiye gıda maddelerinde net ihracatçı olmasına rağmen tarımsal hammaddelerden kaynaklı dış ticaret açığı sebebiyle toplam tarımsal dış ticarette açık vermektedir.

Türkiye'nin tarım sektörü dış ticaretine bakılırken alt kalemlerinin de kendi içerisinde incelenerek yorumlanması gerekmektedir. $\mathrm{Bu}$ çalışmamızda da özellikle bu konuya değinilerek Türkiye'nin tarım sektöründe EİT'si ayrıntılı olarak analize konu edilmektedir.

Tablo 2: 1996-2016 Türkiye Tarımsal Dış Ticaret Rakamları (Değer: Bin ABD \$)

\begin{tabular}{|l|l|l|l|l|l|l|}
\hline \multirow{2}{*}{} & \multicolumn{2}{|c|}{ Toplam Tarım } & \multicolumn{2}{c|}{ Gida Maddeleri } & \multicolumn{2}{c|}{ Tarımsal Hammaddeler } \\
\cline { 2 - 7 } & \multicolumn{1}{|c|}{ İhracat } & \multicolumn{1}{c|}{ İthalat } & \multicolumn{1}{c|}{ İhracat } & \multicolumn{1}{c|}{ Ithalat } & \multicolumn{1}{c|}{ İhracat } & \multicolumn{1}{c|}{ Ithalat } \\
\hline 1996 & 4.948 .628 & 4.866 .236 & 4.556 .596 & 2.830 .932 & 392.032 & 2.035 .304 \\
\hline 1997 & 5.470 .486 & 4.926 .481 & 5.133 .389 & 2.648 .911 & 337.097 & 2.277 .570 \\
\hline 1998 & 5.052 .590 & 4.321 .954 & 4.687 .825 & 2.311 .272 & 364.765 & 2.010 .683 \\
\hline 1999 & 4.441 .540 & 3.398 .370 & 4.084 .736 & 2.038 .217 & 356.804 & 1.360 .153 \\
\hline 2000 & 3.855 .282 & 4.156 .004 & 3.542 .714 & 2.133 .290 & 312.569 & 2.022 .714 \\
\hline 2001 & 4.348 .783 & 2.288 .268 & 3.997 .215 & 1.486 .768 & 351.568 & 801.500 \\
\hline 2002 & 4.052 .178 & 3.994 .918 & 3.668 .207 & 1.911 .832 & 383.971 & 2.083 .087 \\
\hline 2003 & 5.257 .072 & $\underline{5.264 .725}$ & 4.735 .146 & 2.791 .392 & 521.926 & 2.473 .333 \\
\hline 2004 & 6.501 .210 & 6.058 .610 & 5.891 .602 & 3.089 .696 & 609.609 & 2.968 .914 \\
\hline 2005 & 8.308 .537 & 6.480 .289 & 7.713 .679 & 3.284 .265 & 594.859 & 3.196 .024 \\
\hline 2006 & 8.633 .253 & 7.286 .159 & 7.931 .559 & 3.486 .191 & 701.694 & 3.799 .969 \\
\hline 2007 & 9.769 .025 & 9.812 .753 & 9.007 .165 & 5.167 .474 & 761.859 & 4.645 .279 \\
\hline 2008 & 11.473 .866 & 13.037 .582 & 10.705 .380 & 8.502 .792 & 768.486 & 4.534 .790 \\
\hline 2009 & 11.189 .510 & 9.630 .588 & 10.581 .837 & 6.107 .516 & 607.673 & 3.523 .072 \\
\hline 2010 & 12.663 .950 & 12.879 .646 & 11.868 .544 & 7.412 .723 & 795.406 & 5.466 .923 \\
\hline 2011 & 15.279 .137 & 17.574 .453 & 14.207 .482 & 10.652 .831 & 1.071 .655 & 6.921 .621 \\
\hline 2012 & 15.993 .650 & 16.369 .848 & 15.025 .825 & 10.419 .841 & 967.825 & 5.950 .007 \\
\hline 2013 & 17.739 .273 & 16.915 .947 & 16.749 .085 & 10.832 .015 & 990.189 & 6.083 .933 \\
\hline 2014 & 18.746 .898 & 18.059 .765 & 17.746 .937 & 12.048 .697 & 999.962 & 6.011 .068 \\
\hline 2015 & 17.444 .190 & 16.059 .213 & 16.561 .384 & 10.889 .457 & 882.806 & 5.169 .757 \\
\hline 2016 & 16.856 .515 & 15.637 .845 & 16.004 .406 & 10.699 .605 & 852.109 & 4.938 .240 \\
\hline
\end{tabular}

Kaynak: TÜİK

\section{Endüstri İçi Ticaret Teori ve Literatür Özeti}

Uluslararası ticaret ile ilgili modelleri oluşturmak için öncelikle "endüstri”" kavramının iktisadi olarak anlamlı bir biçimde tanımlanması gerekmektedir (Lloyd, 2002: 15). Endüstri kavramı tanımlanırken çoğunlukla malların tüketim ve/veya üretim bağlantıları dikkate alınmaktadır. Bu durumda kavramın oluşturulmasında talep ve arz yönlü olmak üzere iki yaklaşımdan yararlanılmaktadır.
Talep yönlü yaklaşımda endüstri tanımı malların birbirlerine benzerliklerini ve ikame edilebilirliklerini göz önünde bulundurmaktadır. Buna göre "endüstri” yakın ikame olacak kadar birbirine benzeyen malları üreten firmaların oluşturduğu bir gruptur. Arz yönlü yaklaşımda ise malların üretim teknolojilerindeki benzerlikler göz önünde bulundurularak "endüstri” aynı üretim teknolojisini veya aynı 
girdileri kullanarak üretim yapan firmaların olușturduğu bir grup olarak tanımlanmaktadır (Kurul, 2010: 9)

Endüstri tanımı yapıldıktan en sık kullanılan haliyle endüstri içi ticaret, aynı endüstrideki malların eş anlı ithalatı ve ihracatı olarak tanımlanmaktadır (Grubel ve Lloyd, 1975). Bir diğer tanım benzer faktör donanımına sahip endüstrileşmiş ülkeler arasındaki ticarete denilmektedir (Zhang, 2004: 10). Diğer bir ifadeyle, benzer girdi kullanımına sahip olan ve talep yapıları birbirine yakın malların aynı anda bir ülkenin hem ithalat hem de ihracat kalemleri içinde yer almasıdır (Narin, 2002: 7). Bu kavram Balassa (1966), Grubel Lloyd (1975) tarafindan endüstri-içi ticaret, Gray (1980) tarafindan "iki yönlü ticaret", Finger (1979) tarafindan "ticaret genişlemesi", Abd-el Rahman (1986) tarafindan "benzer ürünlerde iki yönlü ticaret” olarak isimlendirmiştir (Şahin, 2015: 173).

Küreselleşmeyle birlikte artan teknolojiye bağlı olarak ticaretin belirleyicileri de değişmiş, ölçek ekonomileri, monopolcü rekabet, ürün farklılaştırması gibi kavramlar klasik ve neoklasik dış ticaret modelleri ile açıklanamamıştır. Ölçek ekonomileri büyük çaplı seri üretimin geçerli olduğu, bu seri üretimi karşılayacak talebin oluştuğu ekonomilerde ve dönemlerde ortaya çıkmışlardır (Ertem, 2011). Bu dönemle birlikte benzer talep ve teknoloji yapısına sahip ülkelerin (Kuzey-Kuzey ve Guney -Guney) diş ticaret hacimlerinin arttığ1 görülmüştür.Endüstri içi ticaret yatay ve dikey olmak üzere ikiye ayrılabilir. Yatay endüstri-içi ticaret belirli bir kalitedeki ürünün farklı özellik ve yönleriyle farklılaştırılması sonucu ortaya çıkan ticarettir. Dikey endüstri-içi ticaret ise farklı kalite düzeyindeki malların karşılıklı ticaretidir (Sahin, 2015:172).

Ekonomik analizlerde genellikle uluslararası ticarete konu olan mallarin Standart Industrial Trade Classification (SITC)'a göre 2 haneli veya 3 haneli düzeylerde toplulaştırılması kullanılmaktadır. Burada toplulaştırma düzeyleri, aynı mal kümesini üreten firmaların oluşturduğu bir grubu temsil etmesi bakımından endüstri kavramına da karş1lık gelmektedir (Grubel ve Lloyd, 1975: 3).

EİT ile ilgili incelenmesi gereken önemli bir konu da EİT'nin ölçülmesidir. EIT'nin birçok ölçüm yöntemi bulunmaktadır. Bunlardan literatürde en fazla kullanılanı Grubel-Lloydölçümüdür. $\mathrm{Bu}$ endekslerden Balassa ve Grubel-Lloydendeksi EIT'nin statik ölçümleri için kullanılırken; Hamilton-Kniest Endeksi, Greenaway-HineMilner-Elliot Endeksi ve Brülhart Endeksleri EIT'nin dinamik ölçüm yöntemleridir. Bunların dışında literatürde kullanılan birçok ölçüm yöntemi bulunmaktadır. Her birinin ölçüm yöntemi eleştiri almıştır.

Çalışmamızda kullanacağımız Grubel-Lloydendeksini ele alacak olursak Grubel ve Lloyd(1975), endüstri içi ticareti ölçen endeksi şu şekilde göstermektedir:

$$
\operatorname{EIT}^{G-L}=1-\frac{|X i-M i|}{(X i+M i)} \cdot 100
$$

Xi ve Mi sırasıyla ele alınan ülkenin j ülkesine i ürün grubu ihracatını ve $\mathrm{j}$ ülkesinden $\mathrm{i}$ ürün grubu ithalatını göstermektedir. Mutlak değer içerisinde gösterilen Xi-Mi, ticaret dengesi işaretinin dikkate alınmadığını, bir başka ifadeyle iki ülke arasında varsa ticaret dengesizliğini endeksin göz ardı ettiğini göstermektedir. Grubel-Lloyd Endeksi (intra-industry trade index ) "endüstri-içi ticaret endeksi”, aynı endüstrideki çift yönlü ticareti göstermekte ve 0 ile 1 arasında değişen değerler almaktadır. Eğer bir ülkenin bir sektördeki ithalat ve ihracatı birbirine oldukça yakın miktarlarda ise endeks 1'e yaklaşır ve söz konusu endüstride endüstri-içi ticaretin varlığına işaret eder. Herhangi bir endüstri/ürün için EİT endeksinin yüksek çıkması söz konusu endüstri/üründe karşılaştırmalı üstünlüğün olmadığını gösterir. Aksi durumda da tersi geçerlidir (Imer ve Utkulu, 2009:9).

Günümüzdeki ticarette hızla artan hacme sahip olan endüstri içi ticarete ilişkin akademik çalışmalar da gittikçe artmaktadır.Rossini ve Burattoni (1999), İtalya'nın AB ve AB-dışı ülkelerle olan EİT'sinin belirlenmesi amacıyla çalışma yapılmıştır. Çalışma sonucunda İtalya'nın AB ülkeleriyle olan EITT'si diğer ülkelerle olan EITT'ye göre daha yüksek çıkmıştır.

Tharakan ve Calfat (1999), Belçika'nın AB ve AB-dışı ülkelerle olan EIT'sinin 1960-1990 dönemi için hesaplanarak; Belçika'nın AB ile olan EITT'sinin Belçika'nın AB-dışı ülkelerle olan EİT'sine göre daha yüksek çıktığı tespit edilmiştir.

Erk ve Tekgül (2001), 1993-1998 dönemi Türkiye ve AB ülkeleri arasında ticarete konu olan 97 ürün grubunun EİT düzeyi ve yatay-dikey farklılaşma düzeylerinin tespiti yapılmıştır. Çalışmaya göre, Türkiye ve $A B$ ülkeleri arasındaki ticaretin önemli bir kısmının EİT yapısında dikey mal farklılaşması şeklinde olduğu tespit edilmiştir.

Erlat ve Erlat (2003), 1969-1999 dönemi için, SITC Rev.3'e göre üç basamaklı sektörel verilerle,15 AB üyesi ülke ile Türkiye'nin EITT'sinin statik ve dinamik yapısını analiz etmiştir. Çalışmada genel olarak ticaretin EAT yapısı sergilediği, ancak özellikle 1980 sonrası dönemde bu yapının az da olsa EİT'ye dönüştüğü gözlemlenmiştir.

Çakmak (2006), Türkiye ile Almanya, İtalya, Fransa ve İngiltere arasında imalat endüstrisi dış ticaretinde EİT'nin yapısını ve önemini tespit etmek için 1991-2004 döneminde SITC Rev.3 üç basamaklı ürün grupları verileri ve standart G-L endeksi kullanılarak bir araştırma yapmıştır. Buna göre ilgili dönemde Türkiye ile dört ülke arasındaki EİT oranlarını temel alan sıralamanın zamanla çok değiştiği sonucuna ulaşmıştır. 1991-2004 döneminin başlarında Türkiye ile imalat endüstrisinde EITT düzeyi en yüksek ülkeler sırasıyla İngiltere, İtalya, Almanya ve Fransa iken, dönemin sonlarına doğru bu sıralamanın Fransa, İtalya, Almanya ve İngiltere biçiminde olduğu tespit edilmiştir.

Kaya ve Atış (2007), Türkiye'nin kimya sanayi ürünleri ithalatı ve ihracatında öne çıkan ülkeler ile EIT'nin gelişimi araştırılmıştır. Çalışmada, Türkiye ile belli başlı AB üyesi ve AB'ye aday ülkeler arasında 1990-2005 dönemi ve SITC Rev.3'e göre beş basamaklı kimya sanayi ürün grubuna ait verilerle, standart G-L endeksi kullanarak statik analiz, daha sonra Brülhart'ın marjinal endüstri-içi ticaretini belirlemeye yönelik A ve B endeksleri kullanarak dinamik analiz yapılmıştır. Çalışmaya göre, Türkiye'nin kimya sanayi EITT düzeyi genel olarak sektör tüketiminin dışa bağımlı olması nedeniyle düşük seviyede gerçekleştiği gözlemlenmiştir.

Bedir (2009), çalışmasında Türkiye'de imalat sanayi endüstrilerini rekabet etme biçimine göre sınıflandırmıştır. Çalışmada endüstri-içi ticaretin ölçümünde Grubel-Lloyd (1971) ve Uyarlanmış Grubel-Lloyd endeksleri kullanılmıştır. 1995-2005 dönemi arası SITC Rev.3 bazında üç basamak 
seviyesinde hesaplanmıştır. Çalışmada sonuç olarak fiyata dayalı rekabet eden endüstrilerde ortalama endüstri-içi ticaretin boyutu düşük ve sabit seyrederken; kaliteye dayalı rekabet eden endüstrilerin ortalama endüstri-içi ticaret oranları daha yüksek çıkmıştır.

Erün (2010), Türkiye ve AB ülkeleri arasında gıda ve canlı hayvan sektörü toplamında ve alt sektöründe 1995-2009 dönemleri itibariyle Grubel - Lloyd endeksi ve birim değer oranları hesaplanmıştır. Türkiye ile AB-15 ülkeleri arasındaki EİT'nin giderek azaldığı ancak tek tek ülkelere bakıldığında özellikle Macaristan, Bulgaristan, Danimarka, İspanya, İrlanda ve Romanya ile olan gıda ve canlı hayvan sektöründe EITT'nin yükseldiği tespit edilmiştir.

Biesebroeck (2011), endüstri-içi ticaretin ayrıntılı incelemesini yaptığı çalışmasında, ABD'nin imalat sanayindeki ticaretinin giderek daha endüstri-içi hale geldiğini, ayrıca aynı durumun Avrupa Birliği ve Çin için de geçerli olduğunu belirtmiştir. Ancak Japonya'da hala endüstriler-arası ticaretin ön planda olduğunu gözlemlemiştir.

Çeştepe (2012), Türkiye'nin Ortadoğu ülkeleriyle olan ticaretinin yapısı analiz edilmiştir. Çalışmada 1999-2009 yılları arasındaki diş ticaret verileriyle ticaret yoğunluğu, Grubel-Lloyd ve Balassa endeksleri ile hesaplanmıştır. Türkiye'nin bu ülkelerle diş ticaretinin arttığı, bu ticarette endüstri içi ticaret düzeyinin genel olarak düşük, işlenmiş mallarda nispeten yüksek olduğu ve Türkiye'nin bir iki mal grubu dışında söz konusu ülke grubuna göre rekabet gücünün bulunduğu görülmüştür.

Özdamar (2014), çalışmada imalat sanayisinin farklı teknoloji düzeyleri bağlamında Türkiye'nin AB (28) ile ticaretinin yapısı ve $\mathrm{AB}$ karşısındaki rekabet gücü, Gümrük Birliği sonrası 1996-2012 dönemi incelemeye konu edilmiştir. Çalışmada endüstri-içi ticaretle ilgili elde edilen bulgular incelendiğinde orta-düşük teknoloji sanayiler, ortaileri teknoloji sanayiler, ileri teknoloji sanayiler grubundaki ve düşük teknoloji sanayiler grubunda farklılıklar arz etmiştir.İlgili endeks değerlerine bakıldığında özellikle ortadüşük teknoloji ve son yıllarda orta-ileri teknoloji sanayiler gruplarında Türkiye-AB arasında endüstri-içi ticaretin yüksek düzeyde olduğu dolayısıyla bu teknoloji gruplarında
Türkiye'nin ya da AB'nin birbirleri karşısında belirgin bir karşılaştırmalı üstünlüğe sahip olmadığı anlaşılmaktadır.

Şahin (2015), çalışmada Türkiye'nin tarımsal gıda ürünlerinin endüstri-içi ticaretinin analizini yapmıştır. Çalışmada ilk olarak Türkiye ve AB-15 ülkelerinin SITC Rev.3 üç basamak sınıflandırmasına göre endüstri-içi ticaret yapısı GL endeksi kullanılarak hesaplanmıştır. Ardından Abd-el Rahman'ın birim değer yöntemi kullanılarak yatay ve dikey endüstri-içi ticaret hesaplanmıştır. Çalışmada sonuç olarak, Türkiye'nin ve AB-15 ülkelerinin seçilmiş tarımsal gıda ürünlerinde gerçekleştirmiş olduğu ticaretin dikey endüstri-içi ticaret şeklinde olduğu görülmüştür.

\section{Veri Seti ve Yöntem}

Endüstri içi ticaret ile ilgili literatürde yaygın olarak Grubel ve Lloyd(1975) tarafindan geliștirilen endeks yer almakta ve analizler hesaplanan bu endeks değerleri üzerinden yapılmaktadır. Çalışmada bu endeks aşağıda yer alan formül ile hesaplanarak kullanılacaktır.

$$
\begin{aligned}
& \text { EİT=1-[|Xi-Mi| / (Xi+Mi)] } \\
& 0 \leq \text { EİT } \leq 1 \\
& \text { Endeks değeri (EİT); }
\end{aligned}
$$

> EITT=0 olduğunda ülke ticaretinde o mal grubunda endüstri içi ticaretin olmadığ 1 yani o mal grubunda yalnız ihracat ya da ithalat yapıldı $\breve{g} 1$,

$>$ EIT $=1$ olduğunda ülke ticaretinde o mal grubunda yapılan ihracat ve ithalatın değerlerinin birbirine yakın olduğu,

$>$ EIT $>\mathbf{0 , 5 0}$ olduğunda endüstri içi ticaretin yüksek olduğu,

$>\mathbf{E I T}<\mathbf{0 , 5 0}$ olduğunda endüstri içi ticaretin düşük olduğu anlaşılmaktadır.

Çalışmada kullanılan tablolar bu değerlendirmeye göre oluşturulmuş olup, tablolarda endüstri içi ticaretin yüksek olduğu durumlar EITT, düşük olduğu durumlar eit sembolleri ile gösterilmiştir.

Analizin yapıldığı datalar TÜİK veri tabanından alınmış olup SITC Revize 3 bazında ve 2 haneli düzeyde tarım sektörü 1996-2016 dönemi y1llık ihracat ve ithalat

\begin{tabular}{|c|c|c|c|c|c|c|}
\hline \multirow{2}{*}{\multicolumn{7}{|c|}{$\begin{array}{l}\text { Tarım (T.T) } \\
\text { Guda Maddeleri (G.M.) }\end{array}$}} \\
\hline & & & & & & \\
\hline \multirow{11}{*}{\multicolumn{2}{|c|}{0}} & & & 0 & & anlı hayvanlar ve gıda maddeleri \\
\hline & & & & 00 & & anlı hayvanlar \\
\hline & & & & 01 & & t ve et ürünleri \\
\hline & & & & 02 & & üt, süt ürünleri ve yumurtalar \\
\hline & & & & 03 & & Salıklar ve diğer deniz ürünleri \\
\hline & & & & 04 & & Iububat, hububat ürünleri \\
\hline & & & & 05 & & Meyve ve sebzeler \\
\hline & & & & 06 & & eker, şeker ürünleri ve bal \\
\hline & & & & 07 & & ahve, çay, kakao, baharat ve ürünleri \\
\hline & & & & 08 & & Tayvanlar için gıda maddeleri \\
\hline & & & & 09 & & eşitli yenilebilir ürünler \\
\hline \multirow{3}{*}{\multicolumn{2}{|c|}{1}} & & & 1 & & çkiler ve tütün \\
\hline & & & & 11 & & ckiler \\
\hline & & & & 12 & & ütün ve tütün mamülleri \\
\hline \multirow{3}{*}{\multicolumn{2}{|c|}{4}} & & & 4 & & Iayvansal, bitkisel katı ve sıvı yağlar, mumlar \\
\hline & & & & 41 & & Tayvansal sıvı ve katı yağlar \\
\hline & & & & 42 & & Tazırlanmış bitkisel sıvı ve katı yağ \\
\hline
\end{tabular}
rakamlarından olușmaktadır.

Tablo 3: SITC Revize 3 Bazında Analize Konu Olan Tarım Sektörü Kalemleri 


\begin{tabular}{|c|l|}
\hline \multicolumn{1}{|c|}{43} & İşlenmiş sıvı, katı yağlar;mumlar \\
\hline 22 & Yağlı tohumlar, yağ veren meyvaler \\
\hline Tarımsal Hammaddeler (T.H.) \\
\hline 21 & İşlenmemiş kösele, deri ve kürk \\
\hline 23 & Ham kauçuk \\
\hline 24 & Mantar, odun ve kereste \\
\hline 25 & Kağıt hamuru ve kullanılmış kağıt \\
\hline 26 & Dokuma elyafı ve bunların artıkları \\
\hline 29 & Başka yerde belirtilmeyen işlenmemiş hayvani, bitkisel ürünler \\
\hline
\end{tabular}

Kaynak: TÜİK

Tarım sektöründe tüm dönem için yıllar itibari ile endüstri içi ticaretin analiz sonuçları şu şekildedir;

Toplam tarımsal ürünlerin dış ticaretine bakıldığında EİT oldukça yüksek gözükmektedir. Yıllar itibari ile en düşük EİT 2001 yılına ait olup değeri 0,69 dur. Bundan sonraki en düşük değer 0,87-0,88 ile 1999 ve 2005 yilına aittir. Daha sonraki değerler ise 0,92-0,99 arasında değişmektedir. 1996 sonrası Türkiye'nin EITT'i oldukça yüksektir.

Toplam tarımsal ürün dış ticareti kendi içerisinde iki ana başlığa ayrılmaktadır. Bunlardan birincisi gıda maddeleri dış ticareti diğeri ise tarımsal hammaddeler diş ticaretidir.

Gıda maddeleri dış ticareti ise kendi içerisinde 4 gruba ayrılmaktadır. Bunlar 0 grubunu oluşturan canlı hayvanlar ve gıda maddeleri, 1 grubunu oluşturan içkiler ve tütün, 4 grubunu oluşturan hayvansal, bitkisel katı ve sıvı yağlar, mumlar ve son olarak 22 grubunu oluşturan yağlı tohumlar, yağ veren meyvelerdir.

- İlk olarak toplam gıda maddelerinin dıș ticaretinin endekslerine göre EİT tüm yıllar için 0,5 değerinden yüksektir. En düşük 0,54 ile 2001 yılının değeri iken en yüksek 0,89 değeri ile 2008 yllına aittir. Diğer değerler ise bu ikisi arasında değişmektedir. Toplam tarımsal ürünlerin diş ticaretine göre EITT düşük olmasına karşıllk yine de oldukça yüksek bir EİT görülmektedir. $\mathrm{Bu}$ kalemin alt gruplarında farklılıklar gözükmektedir.

Gida maddelerinin ilk alt kalemi 0 grubu ile canl hayvanlar ve gıda maddeleridir. $\mathrm{Bu}$ grubun dış ticaretinde bazı dönemlerde EİT'nin düşük bazı dönemlerde yüksek olduğu gözükmektedir. Bu grubun en düşük değeri 0,36 ile 2001 yllına aitken 0,72 değeri ile 2011 yılına aittir. EİT düşük olduğu değerler

ticaretinde bir sabitlik olmayıp sürekli dalgalanma halindedir.

Gıda maddelerinin alt kalemi olan bir diğer ana kalem İçkiler ve tütün (1) kalemidir. Bu kalem de kendi içinde içkiler (11) ve tütün ve tütün mamulleri olarak ikiye ayrılmaktadır. İçkiler ve tütün (1) kaleminin EİT çok yüksek olmamak ile beraber inceleme dönemi boyunca yüksektir. Bu kalemin altında buluna 12 kalemi de aynı şekilde sürekli EİT yüksek seyretmiştir. Ancak 11 kalemi olan içkilerin EİT değeri 9 yıl düşük 12 yıl yüksek gerçekleşmiştir.

Gıda maddelerinin bir diğer alt ana kalemi hayvansal, bitkisel katı ve sıvı yağlar, mumlar (4) kalemidir. Bu kalemde kendi içinde üçe ayrilıp 41, 42, 43 kalemlerinden oluşmaktadır. 4 ana kalemine bakıldığında 2000,2002 ve 2010 yıllarında EİT düşük iken diğer 18 yılda EİT yüksek olarak seyretmektedir. Bu kalemin alt kalemlerinde de yillar itibari ile farklılıklar
0,47(1998), 0,36(2001), 0,40(2005) ve 0,42(2006) olup diğer değerler 0,50 eşik değerinin üstündedir.

0 grubunun alt grubunda olan meyve ve sebzeler (05), kahve, çay, kakao, baharat ve ürünleri (07) ve hayvanlar için gıda maddeleri (08) haricindeki diğer 7 kalem kendi içinde y1llara göre farkl1lık göstermektedir. $\mathrm{Bu} 3$ kalemden meyve sebzeler kalemi sürekli olarak EIT'i düşük olmuştur. Ve değeri 0,09 ile 0,30 arasında değişiklik göstermiştir. Diger bir kalem hayvanlar için gıda maddelerini oluşturan 08 numaralı kalemdir. $\mathrm{Bu}$ kalemde de EİT oldukça düşüktür. Bu kalemin değerleri 0,04-0,24 arasında değişmektedir.

0 grubunun alt kalemlerinden olan 01, 04, 06 ve 09 kalemlerinin değerlerine bakıldığında 2-3 yıl durumlar farklılık gösterip diğer yılların durumları aynıdır. Et ve et ürünleri (01) kaleminde 1996, 2010, 2011 yıllarında EITT oldukça yüksek diğer yılarda ise oldukça düşüktür. Yüksek olduğu 3 yılın ortalaması 0,95 iken diğer 18 yılın ortalaması 0,09 dur. Aynı şekilde 04 ve 09 kalemlerine bakıldığında 19 yıl EİT yüksek 2 yıl ise EİT düşük durumdadır. Burada dikkati çeken kalem hububat, hububat ürünleri (04) kalemidir. 2005 ve 2006 yıllarında bu kalemde EİT düşüktür diğer yıllarda ise yüksektir. 04 kaleminde Türkiye'nin ihracatı ve ithalatı birbirine yakın iken 2005 ve 2006 yıllarında ihracatı ithalatından yaklaşık 4 kat daha fazladır. Yine 0 grubuna ait 06 kaleminde 2 yıl EITT yüksek 19 y1l EİT düşük seyretmiştir. 06 kaleminde şeker, şeker ürünleri ve bal bulunmakta olup 1996 ve 2016 yillarında EİT yüksek olup diğer yıllarda oldukça düşüktür.

0 grubunda bulunan 00,02 ve 03 kalemlerine bakıldığında bazı yıllar EITT yüksek bazı yıllarda EITT düşük olmuştur. Kısaca bu üç kalemin dış gözükmektedir. $\mathrm{Bu}$ ana kalemin alt kalemleri itibari ile sabit bir seyri bulunmayıp farklılıklar arz etmektedir.

Gıda maddelerinin son kalemi yağlı tohumlar, yağ veren meyveler (22) kalemidir. Gida maddeleri ana başlıklarından sadece bu kalemin yıl boyunca EITT düşük seyretmektedir. 22 kaleminin en düşük değeri 0,13 olup en yüksek değeri 0,31 dir. Diğer değerler bu ikisi arasında yıllar itibari ile değişmektedir. Bu kalemde Türkiye sürekli dış ticaret açığı vermektedir.

Tarımsal hammaddelerin dış ticaretinin analiz sonuçları;

Tarımsal hammaddeler ana kaleminin altında 21, 23, 24, 25,26 ve 29 kalemleri bulunmaktadır. Bunların toplamı olan tarımsal hammaddeler ana kaleminin sonuçlarına bakıldığında bütün yıllarda EİT'nin düşük olduğu gözükmektedir. En düşük değer 0,25 iken en yüksek değer 0,42 olup genele bakıldığında yıllar itibari ile 0,30 değerinin altındadır. 
- Tarımsal hammaddeler ana kaleminin altında bulunan kalemleri belirgin şekilde ikiye ayırmak mümkündür. İlk 5 kalem de $(21,23,24,25,26)$ iki yıl hariç(26 kaleminden kaynaklı iki yıl) bütün yıllarda EİT düşüktür. Sonuncu kalem olan başka yerlerde belirtilmeyen işlenmemiş hayvani, bitkisel ürünler kaleminde ise EITT bütün yıllarda yüksek çıkmıştır.
Tarımsal hammaddeler kaleminin ilk dört kalemi (21, 23, 24 ve 25 ) ayrıntılı olarak incelendiğinde EIT'nin oldukça düşük olduğu gözükmektedir.

Tablo 4. Tarımsal Ürünlerde Endüstri İçi Ticaret (1996-2002)

\begin{tabular}{|c|c|c|c|c|c|c|c|c|c|c|c|c|c|c|}
\hline & \multicolumn{2}{|c|}{1996} & \multicolumn{2}{|c|}{1997} & \multicolumn{2}{|c|}{1998} & \multicolumn{2}{|c|}{1999} & \multicolumn{2}{|c|}{2000} & \multicolumn{2}{|c|}{2001} & \multicolumn{2}{|c|}{2002} \\
\hline & G-L & Dur. & G-L & Dur. & G-L & Dur. & G-L & Dur. & G-L & Dur. & G-L & Dur. & G-L & Dur. \\
\hline T. T. & 0,99 & EITT & 0,95 & EIT & 0,92 & EITT & 0,87 & EITT & 0,96 & EIT & 0,83 & EİT & 0,99 & EITT \\
\hline G. M. & 0,77 & EITT & 0,68 & EIT & 0,66 & EIT & 0,67 & EİT & 0,75 & EIT & 0,54 & EIT & 0,69 & EİT \\
\hline T.H. & 0,32 & eit & 0,26 & eit & 0,31 & eit & 0,42 & Eit & 0,27 & Eit & 0,36 & eit & 0,31 & eit \\
\hline
\end{tabular}

Kaynak: TÜİK veYazarın Kendi Hesaplamaları

Tablo 5. Tarımsal Ürünlerde Endüstri İçi Ticaret (2003-2009)

\begin{tabular}{|c|c|c|c|c|c|c|c|c|c|c|c|c|c|c|}
\hline & \multicolumn{2}{|c|}{2003} & \multicolumn{2}{|c|}{2004} & \multicolumn{2}{|c|}{2005} & \multicolumn{2}{|c|}{2006} & \multicolumn{2}{|c|}{2007} & \multicolumn{2}{|c|}{2008} & \multicolumn{2}{|c|}{2009} \\
\hline & G-L & Dur. & G-L & Dur. & G-L & Dur. & G-L & Dur. & G-L & Dur. & G-L & Dur. & G-L & Dur. \\
\hline T. T. & 1,00 & EİT & 0,96 & EITT & 0,88 & EİT & 0,92 & EİT & 1,00 & EİT & 0,94 & EİT & 0,93 & EİT \\
\hline G. M. & 0,74 & EİT & 0,69 & EITT & 0,60 & EIT & 0,61 & EİT & 0,73 & EİT & 0,89 & EİT & 0,73 & EİT \\
\hline T.H. & 0,35 & eit & 0,34 & eit & 0,31 & eit & 0,31 & eit & 0,28 & eit & 0,29 & eit & 0,29 & eit \\
\hline
\end{tabular}

Kaynak:TÜİK veYazarın Kendi Hesaplamaları

Tablo 6. Tarımsal Ürünlerde Endüstri İçi Ticaret (2010-2016)

\begin{tabular}{|c|c|c|c|c|c|c|c|c|c|c|c|c|c|c|}
\hline & \multicolumn{2}{|c|}{2010} & \multicolumn{2}{|c|}{2011} & \multicolumn{2}{|c|}{2012} & \multicolumn{2}{|c|}{2013} & \multicolumn{2}{|c|}{2014} & \multicolumn{2}{|c|}{2015} & \multicolumn{2}{|c|}{2016} \\
\hline & G-L & Dur. & G-L & Dur. & G-L & Dur. & G-L & Dur. & G-L & Dur. & G-L & Dur. & G-L & Dur. \\
\hline T. T. & 0,99 & EITT & 0,93 & EİT & 0,99 & EIT & 0,98 & EİT & 0,98 & EITT & 0,96 & EIT & 0,96 & EIT \\
\hline G. M. & 0,77 & EİT & 0,86 & EİT & 0,82 & EITT & 0,79 & EIT & 0,81 & EITT & 0,79 & EIT & 0,80 & EIT \\
\hline T.H. & 0,25 & eit & 0,27 & eit & 0,28 & eit & 0,28 & eit & 0,29 & eit & 0,29 & eit & 0,29 & eit \\
\hline
\end{tabular}

Kaynak:TÜİK veYazarın Kendi Hesaplamaları

\section{Sonuc}

Endüstri-içi ticaret diş ticarette en yaygın olarak görülen ticaret şekillerinden biridir. Gelişmiş ülkeler arasında gözlenen endüstri-içi ticaret gelişmiş ülkelerin gelişmekte olan ülkeler ile ya da gelişmekte olan ülkelerin kendi aralarındaki ticareti için de araştırmalara konu olmaktadır. EITT hesaplamalarında en çok kullanılan yöntem GrubelLloyd endeksidir. Bu çalışmada da söz konusu endeks kullanılmış ve elde edilen sonuçlar detaylı olarak analiz edilmiştir.

Çalışma sonucunda Türkiye'nin tarım sektöründe yüksek düzeyde endüstri-içi ticareti tespit edilmiştir. Ancak toplam tarımsal dış ticaret için söylenebilen bu durum tarımsal dış ticaretin alt kalemlerinde farklılıklar arz etmiştir. Analiz sonucu çıkan sonuçlara göre;

Türkiye'nin tarım sektörü endüstri içi ticareti oldukça yüksektir. Bu da gösteriyor ki tarımsal ihracat ve ithalat birbirine oldukça yakındır. Yıllar itibari ile bakıldığında 2001, 2003, 2007, 2008, 2010, 2011, 2012 yillarında tarımsal dış ticaret açı̆̆ı verilmiş olup diğer yıllarda tarımsal dıș ticaret fazlası verilmiştir. Bu değișimlere karşılık ithalat ve ihracattaki fark çok olmadığ 1 için EİT yüksek çıkmıştır. 1996-2016 döneminde ihracat ve ithalat arasındaki farklar 7 milyon TL ile 2 Milyar TL arasında değişim göstermiştir.

> Toplam tarımsal dış ticarette EİT’nin yüksek olmasına karşılık alt kalemler de farklılıklar gözlemlenmiştir.

> Türkiye gıda maddeleri dış ticaretinde EİT yüksek çıkmıştır. Ancak bu yüksek oran toplam tarımsal dış ticarete oranla düşüktür. Gıda maddeleri dış ticaretinde hiçbir zaman dış ticaret açığı verilmemiş olup daima ihracat fazlası gözlemlenmiştir.

$>$ Gıda maddeleri ana kalemi altında dört kalemde EITT sürekli düşük çıkmış olup bunlar meyve ve sebzeler, hayvanlar için gıda maddeleri, hayvansal sıvı ve katı yağlar ile yağlı tohumlar, yağ veren meyveler dış ticaretidir. Bu kalemlerin dördünde de EİT'nin düşük çıkma sebebi farklıdır. Meyve ve sebzeler kaleminde Türkiye net dış ticaret fazlası veren bir ülke olup ithalata oran ile oldukça fazla ihracat yapmaktadır. Bu fazlalık yaklaşık 20-25 kat daha fazla ihracat olarak tespit edilmiştir. $\mathrm{Bu}$ kalem aksine diğer 3 kalemin diş ticaretinde ise Türkiye sürekli dış ticaret açığı veren bir ülke pozisyonundadır. Bu sebep ile bu kalemlerde de EİT düşük çıkmıştır.

> Toplam tarımsal diş ticareti oluşturan diğer ana kalem tarımsal hammaddelerdir. Türkiye 1996-2016 dönemi boyunca bu kalem bazında sürekli dış ticaret açığı vermiștir. Ve bu açık oldukça yüksektir. Bu kalemde Türkiye EIT'i oldukça düşük çıkmasının sebebi de budur.

$\mathrm{Bu}$ sonuçlara göre toplam tarımsal dış ticarette EİT yüksek çıkmıştır. Kısaca Türkiye'nin son 21 yılda tarım sektöründe ithalatı ile ihracatının arasındaki fark düşüktür. Burada dikkat edilmesi gereken husus gida maddeleri ile tarımsal hammaddeler arasındaki farktır. Gıda maddeleri dış ticaretinde EITT yüksek çıkmasına karşılık tarımsal hammaddeler ticaretinde oldukça düşüktür. Sonuç olarak; Türkiye gıda maddeleri ticaretinde endüstri içi ticaret avantajından faydalanmakta ve potansiyel bir rekabet avantajı sağlamaktadır. Ancak, tarımsal hammadde ticaretinde düşük 
endüstri içi ticaret bu alt sektörde rekabette geri olduğumuz sonucunu ortaya koymaktadır. Tarımsal hammadde ticaretinde potansiyel rekabet avantajı sağlanamamasının en büyük nedeni işlenmiş ürün ihracatıdır. İşlenmiş ürün ihracatını desteklemek için tarım hammaddesi ithal etmek bu alt sektörde rekabet gücünü düşürmektedir. $\mathrm{Bu}$ yüzden tarımsal hammadde ithalatı yerine yurtiçi üretime öncelik vermek gerekmektedir. Aksi takdirde Türkiye tarımsal hammadde de dışa bağımlılı̆̆ı konumunu sürdürmeye devam edecektir.

\section{Kaynaklar}

BEDİR, A., (2009). Uluslararası Ticarette Fiyata Dayal Rekabet Gücü ile Endüstri-İçi Ticaret Arasındaki İlişki: Türk İmalat Sanayi Örneği. DPT ISBN978-975-19-4482-5, 1-223.

BİESEBROECK, J. V., (2011). Dissecting IntraIn $\neg$ dustry Trade, Economics Letters: 110, 71-75.

ÇAKMAK, Ö., (2006). Türkiye ile Almanya, İtalya, Fransa ve İngiltereArasında İmalat Endüstrisinde Endüstri-İçi Ticaretin Yapısı: 1991-2004. Ekonomik ve Sosyal Araştırmalar Dergisi, 3(1), 30-47.

ÇEŞTEPE, H., (2012). Türkiye'nin Seçilmiş Ortadoğu Ülkeleriyle Ticaretinin Analizi. Ekonomik ve Sosyal Araştırmalar Dergisi, 8( 2), 23-43.

ERK, N., ve TEKGÜL, Y., (2001). Ekonomik Entegrasyon ve Endüstri-İçi Ticaret: Türkiye- AB Ülkeleri arasındaki Endüstri-içi Ticaretin Ölçülmesi ve Ticaret Tipinin Belirlenmesi. METU International Conference on Econo $\neg$ mics V, 1-34.

ERLAT, G., ve ERLAT, H., (2003). Measuring IntraIndustry and Marginal Intra-Industry Trade: The Case for Turkey. Emerging Markets Finance and Trade, 39(6), 5-38.

ERTEM, Cemil (2011). Türkiye İcin Alternatif Büyüme Perspektifleri ve Yeni Kalkınma Modellemesine Giriş, Yayınlanmamış Doktora Tezi, Sosyal Bilimler Enstitüsü, İstanbul Üniversitesi

ERÜN, G., (2010). Türkiye ile AB, Gıda ve Canlı Hayvan Sektörü Dış Ticaretinde Endüstri-İçi Ticaret Analizi. Ekonomi Bilimleri Dergisi, 2(1), 71-78.

GRUBEL, Herbert Gunter ve LLOYD, Paul (1975). IntraIndustry Trade: The Theory and Measurement of International Trade in Differentiated Products, Wiley \& Sons, New York: John.

KAYA, A., ve ATIŞ, A., (2007). Türkiye Kimya Sanayi Endüstri-İçi Ticaretinin Statik ve Di $\neg$ namik Analizi: Avrupa Birliği Üye ve Aday Ülkeleri, Rusya Federasyonu, Ukrayna ve Çin. Ege Akademik Bakış, 7(1), 251-291.

KURUL, Zühal (2010). AB ve Gümrük Birliği'nin Endüstri İçi Ticaret Üzerindeki Etkisi ve Endüstri İçi Ticaretin Belirleyenleri, Yüksek Lisans Tezi, Hacettepe Üniversitesi Sosyal Bilimler Enstitüsü.

LLOYD, Paul ve LEE, Hyun-Hoon (2002).Frontiers of Research in Intra-Industry Trade, Palgrave Macmillan Ltd., New York.

NARIN, Pınar. (2002). "Endüstri-içi Ticaret ve İh $\neg$ racata Dayalı Sektörler Açısından Türkiye Uygulaması", Dokuz Eylül Üniversitesi Sosyal Bilimler Enstitüsü Dergisi, 4(1), ss. $1-212$.

ÖZDAMAR, G., (2014). İmalat Sanayisinde Türkiye'nin AB İle Ticaretinin Yapısı ve Rekabet Gücü: Teknoloji
Düzeylerine Göre Bir İnceleme. Dumlupınar Üniversitesi Sosyal Bilimler Dergisi, 41, 11-30.

ROSSINI, G., and BURATTONI, M., (1999). Country Analysis: Italy, Intra-Industry Trade and Adjustment: The European Experience Palgrave. Macmillan Hampshire, England.

ŞAHIN, Dilek (2015). “Türkiye'nin Tarımsal Gıda Ürünlerinin Endüstri-İçi Ticaretinin Analizi: AB-15 Ülkeleri ile Karşılaştırmalı Analiz", Uluslararası Hakemli Ekonomi Yönetimi Araştırmaları Dergisi, Sayı: 4, ss. 171-192.

THARAKAN, P. and CALFAT, G., (1999). Co $\neg$ untry Analysis: Belgium, Intra-Industry Trade and Adjustment: The European Experience Palgrave. Macmillan, Hampshire, England.

TYDTA (2017), Tarim ve Gida, http://www.invest.gov.tr/tr-

TR/sectors/Pages/Agriculture.aspx, (02.05.2017)

TÜİK (2008). Diş Ticaret İstatistikleri ve Endeksleri, Sorularla Resmi İstatistikler Dizisi-2, Ankara.

TÜİK (2016). Dış Ticaret İstatistikleri ve Endeksleri, Ankara.

UTKULU, Utku ve Hayriye İMER; (2009). “Türk Tekstil ve Konfeksiyon Sektörünün Avrupa Birliği Tekstil ve Konfeksiyon Sektörü Karşısındaki Rekabet Gücünün Alt Sektörler Düzeyinde Ölçülmesi (1994-2005)", http://www.rekabet.gov.tr/File/?path=ROOT\%2F1\%2FDocu ments\%2FRekabet\%2BDergisi\%2Fderg 36.pdf, (Son Erişim Tarihi: 23.02.2017).

ZAHANG, Zhaoyong (2004). "Country-specific Factors and the Pattern of Intra-Industry Trade in China's Manufacturing", Korea Institute for International Economic Policy (KIEP) CNAEC Research Series, 04-01, ss. 1-31. 